\title{
Research on Safety Spacing of Chemical Storage Tanks Based on Accident Consequence and Risk Analysis
}

\author{
Zhenping $\mathrm{Li}^{1}$, Sanming Wang ${ }^{2}$, and Dongliang $\operatorname{Sun}^{3}$ \\ ${ }^{1}$ Communication and Information Center, Ministry of Emergency Management of the People's Republic of China, Beijing 100000, China \\ ${ }^{2}$ Nanjing Anyuan Technonlogy Company Limited, Nanjing 210009, China \\ ${ }^{3}$ East China University of Science and Technology, Shanghai 200000, China
}

\begin{abstract}
The placement of chemical storage tanks is an important topic in industrial safety, and its placement method is based on the study of the safety spacing of storage tanks. This paper takes LPG and LNG storage tanks as examples. It uses vapor cloud explosions, pool fires, pressure vessel explosions, boiling liquid expansion vapor explosions and other fire and explosion accident consequences models and risk probability analysis methods to analyze. It is proved that the transfer of storage tanks from ground to underground can significantly reduce the scope of impact of explosion accidents, thereby increasing the utilization rate of industrial land.
\end{abstract}

\section{PREFACE}

Since the reform and opening up, China's industry has developed rapidly, but most of China's industrial land has not been properly planned and used. The area of industrial land accounts for a large proportion of urban space, and the floor area ratio is very low. The fire separation distance determined by the existing technical specifications cannot increase the utilization rate of the land and reduce the scope of the accident.

A. Marangon et al.[1] proposed the "safe distance" analysis process and method for analyzing fuel hydrogen storage facilities. S. Sudheer et al.[2] analyzed the safety distance based on thermal radiation, obtained pool fire thermal images by thermal infrared imaging instrument, calculated the irradiance of different positions, and determined the critical heat flux limit for humans. J.L. Rossi et al.[3] obtained a method to approximate the safety distance by analyzing the fixed radiation threshold. Yu Jianping[4] used geotechnical explosion theory to study buried gasoline storage tanks and established a calculation method for the effects of buried explosions[6].

This topic is based on previous studies, taking the essence of it, and using the accident consequence model and risk analysis method to study the impact distance of storage tanks.

\section{METHOD}

This project takes the setting of chemical storage tanks as the starting point, and selects the technical methods widely used in China, the technical methods specified by CCPS and TNO, and the previous wind tunnel tests. Apply pool fire[7], jet fire, fireball, boiling liquid expansion vapor explosion[8], vapor cloud explosion[9], pressure vessel explosion and underground explosion and other fire and explosion accident consequence models and risk probability analysis methods to Study the safe distance of liquid oxygen, hydrogen, LPG, LNG and gasoline storage tanks under different settings.

\section{Core content research}

\subsection{Underground LPG storage tank}

LPG is a flammable liquefied gas. When the storage tank is stored underground, the occurrence of accidents is divided into two analysis: the first is the explosion of the steam cloud in the fire source after the storage tank leaks. When the explosion breaks through the top of the space, the contents of the storage tank are burnt by pool fire, or BLEVE directly occurs; the second is that the pressure inside the storage tank increases sharply and the pressure vessel explodes. All explosion models convert the generated energy into TNT equivalent, and then use the Lekhoff underground explosion model to calculate the range of influence.

(1) Analysis of vapor cloud explosion

After the LPG leaks, it vaporizes quickly and forms a gas cloud around the storage tank. Because it is in the underground space, the steam cloud explosion in the enclosed space occurs in the LPG. The explosion mainly affects the outside in the form of shock waves. The explosion process of the LPG tank in the underground space is that the shock wave first breaks through the roof of the space and then affects the outside. 


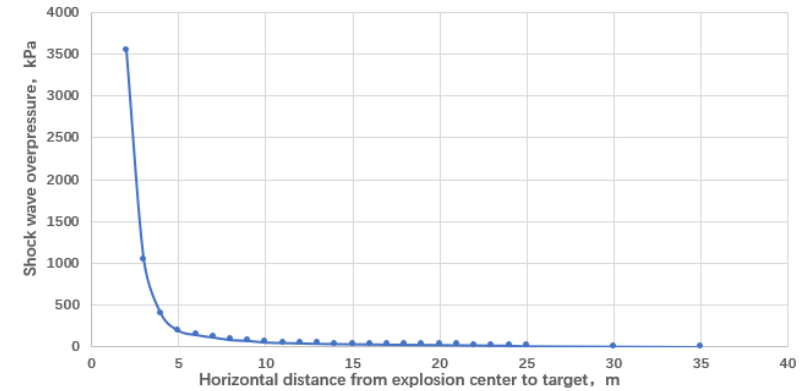

Fig. 1. Relationship between over-pressure and distance Using the accident consequence model to calculate, the explosion energy that LPG can release when the container ruptures is $5.44 \times 10^{8} \mathrm{~J}$, which is converted into TNT equivalent of $121 \mathrm{~kg}$.

Through graphical analysis, it is found that the radiation radius of the explosion of an underground LPG tank is $23.948 \mathrm{~m}$, and the calculated safety distance is $22.421 \mathrm{~m}$.

(2) Pool fire analysis

The storage tank in the underground space bursts through the roof after an explosion, and the tank room where the storage tank is located will form a liquid pool. At this time, it is necessary to calculate the heat radiation effect of a fire in the liquid pool. Through calculation, the heat emissivity SEP of the pool fire is $5.23 \times$ $10^{4} \mathrm{~J} /\left(\mathrm{m}^{2} \cdot \mathrm{s}\right)$. The relationship between the heat radiation flux produced by the pool fire and the target distance is shown in Figure 2. When the horizontal distance from the center of the pool fire flame is $5.29 \mathrm{~m}$, the heat radiation flux drops to $12.5 \mathrm{~kW} / \mathrm{m}^{2}$, and the calculated safety distance of the storage tank is $5.29 \mathrm{~m}$.

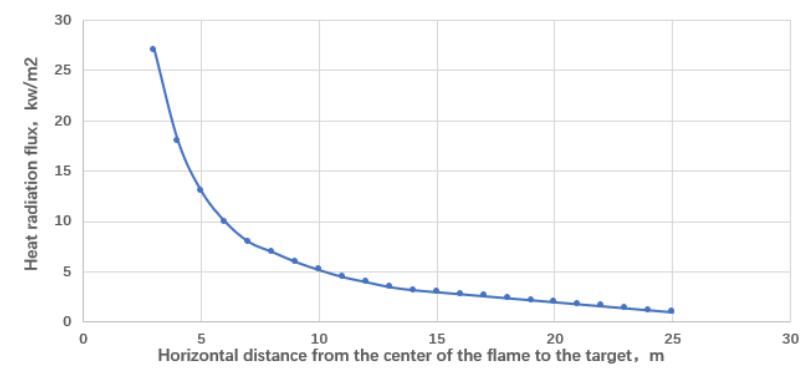

Fig. 2. The relationship between heat flux and distance

(3) Analysis of pressure vessel explosion

When the internal pressure of the LPG storage tank exceeds the capacity of the storage tank, a physical explosion of the container will occur. A large amount of gas will be released in the form of over-pressure shock waves, which will affect the surrounding after breaking through the roof. The over-pressure and impact distance caused by the explosion are shown in Figure 3. When the shock wave over-pressure drops to $2.07 \mathrm{kPa}$ at a position $17.675 \mathrm{~m}$ from the explosion center, the calculated value of the safe distance from the outer wall of the tank to the target is $16.148 \mathrm{~m}$.

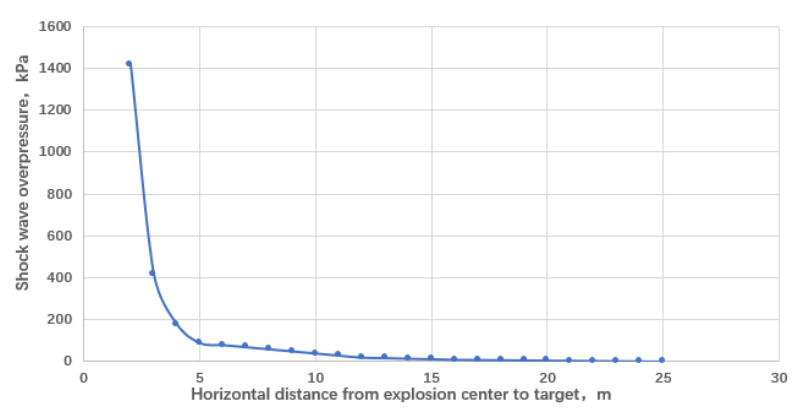

Fig. 3. Relationship between over-pressure and distance

(4) Analysis of the impact of BLEVE explosion shock wave.

The instantaneous temperature when the liquefied gas storage tank explodes will have a certain impact on the distance of the explosion overpressure. The instantaneous temperature of the LPG explosion is between the critical temperature and the boiling point of the liquid, that is, $231.08 \mathrm{~K} \leqslant \mathrm{TO}<403.79 \mathrm{~K}$. Establish the explosion influence distance and instantaneous temperature curve when the overpressure is $2070 \mathrm{~Pa}$, as shown in Figure 4.

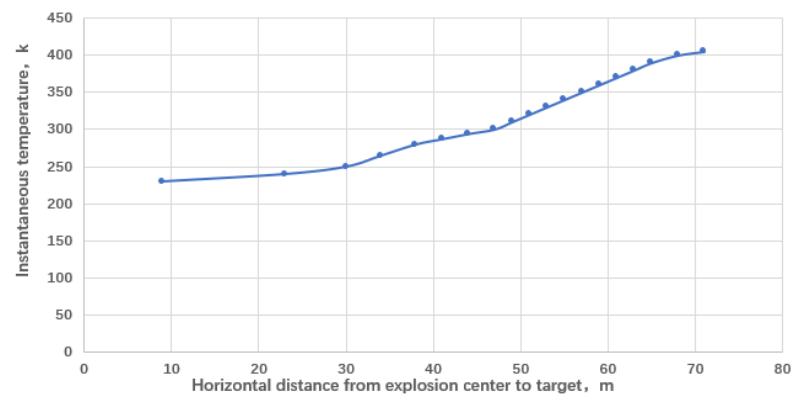

Fig. 4. The relationship between instantaneous temperature and distance $(\triangle \mathrm{P}=2070 \mathrm{~Pa})$

From Figure 4, it can be found that the influence distance increases with the increase of instantaneous temperature, and the distance from the explosion center to the target is between $9.605 \mathrm{~m}$ and $71.224 \mathrm{~m}$.

(5) Analysis of the influence distance of BLEVE explosive fragments

Regardless of the influence of the roof of the underground space and the outer wall of the storage tank on the explosive debris, the debris with a mass of $2 \mathrm{~kg}$ is set to be ejected at $45^{\circ}$, and the maximum flight trajectory of the debris ejection can be obtained by calculation, as shown in Figure 5. The target building is set to four-level fire resistance, that is, the roof is made of colored steel tiles, the beams and walls are made of wood, the impact of debris on the wall during the ascending phase, and the impact on the roof during the descending phase is analyzed, as shown in Figure 6. 


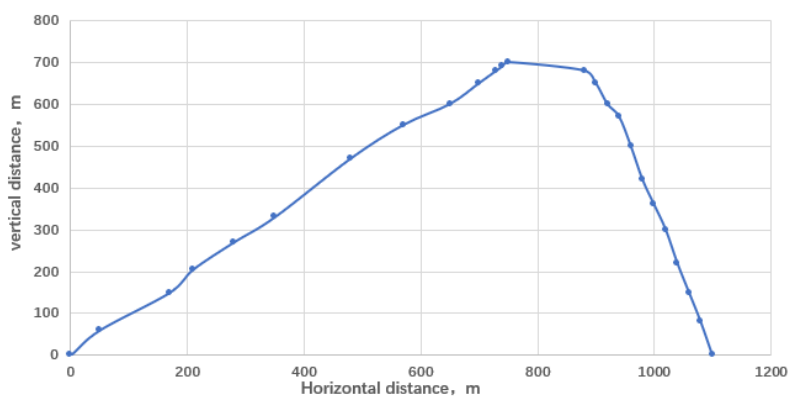

Fig. 5. Explosive debris flight path

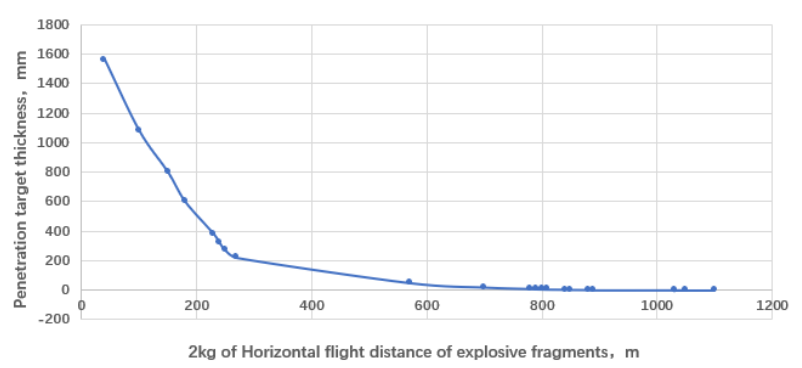

Fig. 6. The relationship between the flying distance of explosive fragments and the thickness of the penetrated target

Through analysis, it can be found that explosive fragments have greater kinetic energy during the ascending phase, and are more harmful. They have penetrating damage to the fourth-level buildings within the range of $329.624 \mathrm{~m}$, while in the descending phase, the kinetic energy generated is mainly generated by gravity. It is not enough to penetrate the colored steel tile roof, so it is believed that the damage to the target when the debris falls is within an acceptable range.

According to the calculation based on the outer wall of the storage tank is made of steel and the roof of the underground space is made of $20 \mathrm{~cm}$ concrete material, the explosion-generated fragments need to consume energy to break through the two lines of defense. 3.223 $\times 10^{6} \mathrm{~J}$, which is greater than the initial kinetic energy of the explosion fragments $9.06 \times 10^{5} \mathrm{~J}$. Therefore, the explosion of the storage tank in the underground space does not consider the impact of debris.

(6) Summary

Underground LPG storage tank explosion accidents include pool fires, boiling liquid steam explosions, vapor cloud explosions, and pressure vessel explosions. The safety distance calculation values generated by these accident types are weighted and redundantly processed to obtain the final safety distance calculation value of the LPG tank.

Table 1. LPG storage tank accident distance calculation value

\begin{tabular}{ccccccc}
\multicolumn{9}{c}{ (unit: $\mathrm{m}$ ) } & & \\
\hline $\begin{array}{c}\text { BELVE } \\
\text { Shock } \\
\text { wave }\end{array}$ & $\begin{array}{c}\text { Poolfire } \\
\text { Heat } \\
\text { radiation }\end{array}$ & $\begin{array}{c}\text { UVCE } \\
\text { Shock } \\
\text { wave }\end{array}$ & $\begin{array}{c}\text { CPE } \\
\text { Shock } \\
\text { wave }\end{array}$ & $\begin{array}{c}\text { weighte } \\
\text { d }\end{array}$ & $\begin{array}{c}\text { redunda } \\
\text { ncy }\end{array}$ \\
\hline $\begin{array}{c}8.078- \\
69.697\end{array}$ & 5.29 & 22.421 & 16.148 & $\begin{array}{c}7.61- \\
22.04\end{array}$ & $\begin{array}{c}7.99- \\
23.14\end{array}$ \\
\hline
\end{tabular}

The LPG storage tank is underground, so that the debris generated by the explosion cannot act on the ground target. The minimum safety distance is $7.99 \mathrm{~m}$ and the maximum is $23.14 \mathrm{~m}$. The fire separation distance between the LPG storage tank and the fourthclass fire-resistant building is $30 \mathrm{~m}$. Therefore, it is believed that LPG storage tanks located in underground spaces can effectively reduce land use and reduce the risk of accidents.

\subsection{Underground LNG storage tank}

LNG storage tanks have constituted a major source of danger. Risk analysis and assessment methods are used to calculate the safety distance. The entire calculation process is divided into four contents: basic data collection and determination (including natural conditions, population data, leakage probability, ignition probability), Calculation of death probability, personal risk calculation, and social risk calculation of various accident types, and finally determine the safety distance of the storage tank.

(1) The safety distance calculated according to 16 directions has extremely low values such as $0 \mathrm{~m}$ and $1 \mathrm{~m}$. The death probability of pool fire, pressure vessel explosion and BLEVE overpressure at this distance are all $100 \%$, so it needs to be corrected. Correct $0 \mathrm{~m}$ and $1 \mathrm{~m}$ to the next lowest value of the corresponding item. Taking the four directions of east, west, south and north as examples, the revised safety distance is shown in Table 2.

Table 2. Corrected safety distance (unit: $\mathrm{m}$ )

\begin{tabular}{|c|c|c|c|c|c|c|c|c|}
\hline position & \multicolumn{2}{|c|}{$\mathrm{N}$} & \multicolumn{2}{|c|}{$\mathrm{E}$} & \multicolumn{2}{|c|}{$\mathrm{S}$} & \multicolumn{2}{|c|}{ W } \\
\hline $\begin{array}{l}\text { density } \\
\text { area }\end{array}$ & 220 & 70 & 140 & 70 & 170 & 70 & 81 & 70 \\
\hline $\begin{array}{c}\text { Moderate } \\
\text { density } \\
\text { area }\end{array}$ & 247 & 220 & 247 & 140 & 247 & 170 & 100 & 81 \\
\hline $\begin{array}{l}\text { High } \\
\text { density } \\
\text { area }\end{array}$ & & & & 47 & & & 247 & 100 \\
\hline
\end{tabular}

Note: The left side of the table is the distance of new projects, and the right side is the distance of built projects.

(2) The analysis believes that a $5000 \mathrm{~m}^{3}$ LNG storage tank buried in the ground can effectively eliminate the impact of explosion debris and reduce the impact of thermal radiation and shock waves. Although the explosion risk of storage tanks cannot be avoided, the social risk is placed in the "risk as low as possible zone" through buried installation, that is, strict management and technical measures can be adopted to ensure that the explosion risk is controllable.

\section{Conclusion}

This paper studies and analyzes the influence of the storage tank setting method on the safety distance. Through research and analysis, we have a certain understanding of the influence law of combustionsupporting substances, combustible gas, combustible liquid, gas concentration diffusion, thermal radiation, shock wave, debris, etc. on the surroundings. 
The main research work and conclusions are as follows:

(1) When there is an explosive storage tank installed underground (or buried), the impact of explosive debris can be effectively eliminated by setting a partition between the storage tank and the ground. The initial kinetic energy of the explosion fragments of an $80 \mathrm{~m}^{3}$ LPG storage tank is $9.06 \times 10^{5} \mathrm{~J}$, and the initial kinetic energy of the explosion fragments of a $5000 \mathrm{~m}^{3} \mathrm{LNG}$ storage tank is $1.87 \times 10^{7} \mathrm{~J}$, both of which are less than the energy consumption required to penetrate a $20 \mathrm{~cm}$ concrete underground roof.

(2) The analysis of the accident consequence analysis method found that the impact of the explosion of the storage tank is more significant than that of the fire. Regardless of the impact of explosion, the safety distance generated by the thermal radiation of the underground (or buried) chemical storage tank is much lower than the fire separation distance value in the code.The thermal radiation influence range of underground LPG storage tanks is $7.99 \mathrm{~m} \sim 23.14 \mathrm{~m}$ (the fire separation distance is $30 \mathrm{~m}$ ).

(3) The application of risk analysis and assessment methods found that the buried installation of $5000 \mathrm{~m}^{3}$ LNG storage tanks can effectively eliminate the impact of explosion debris, reduce the impact of thermal radiation and shock waves, and make social risks in the "risk as low as possible". That is, strict management and technical measures can ensure that the explosion risk is controllable.

(4) Applying the fire and explosion accident consequence model and risk analysis and assessment methods to analyze the relationship between the storage tank setting mode and the safety distance, it is proved that the transfer of storage tanks from ground to underground can significantly reduce the scope of impact of explosion accidents, thereby increasing the utilization rate of industrial land.

\section{Acknowledgments}

This article is one of the phased achievements of the key special project of the national key research and development plan (No. 2016YFC0800105).

\section{References}

1. Marangon A, Carcassi M, Engebø A, et al. Safety distances: Definition and values[J]. International Journal of Hydrogen Energy, 2007, 32(13):21922197.

2. Sudheer S, Kumar L, Manjunath B S, et al. Fire safety distances for open pool fires[J]. Infrared Physics \& Technology, 2013, 61(6):265-273.

3. Rossi J L, Simeoni A, Moretti B, et al. An analytical model based on radiative heating for the determination of safety distances for wildland fires[J]. Fire Safety Journal, 2011, 46(8):520-527.

4. Yu Jianping, Zhang Lijing, et al. The minimum safety distance under the heat radiation of pool
fire[J]. China Safety Science Journal, 2004, 14(3): 16-19.

5. Luo Aimin, et al. Treatment technology for hidden dangers of insufficient fire separation distance of liquid oxygen tanks[J]. China Production Safety Science and Technology, 2011, 7(11): 147-150.

6. Xiao Li. Forced Deformation Test and Simulation Research on Large-scale LNG Underground Storage Tank[J]. Chinese Journal of Underground Space and Engineering, 2020, 16(S1):63-70.

7. Gao Jindong. Risk assessment on domino effect caused by pool fire in chemical tanks[J]. Journal of Safety Science and Technology, 2013, 9(07):54-59.

8. Huang Quanlei, Sun Baoping. Research on BLEVE accident of liquefied petroleum gas[J]. Journal of Safety Science and Technology, 2017,13(07):173179.

9. Ge Peng. Quantitative Analysis of the Consequences of Steam Cloud Explosion Caused by the Leakage of LNG Storage Tanks[J]. Inner Mongolia Petrochemical Industry, 2014, 40(11):76-78. 